\title{
Exocrine Pancreatic Cancer pT3 TNM
}

\section{Finding v8}

National Cancer Institute

\section{Source}

National Cancer Institute. Exocrine Pancreatic Cancer pT3 TNM Finding v8. NCI

Thesaurus. Code C134894.

Exocrine pancreatic cancer with tumor measuring more than $4 \mathrm{~cm}$ in greatest dimension. (from AJCC 8th Ed.) 